\title{
Caracterização físico-química e análises por espectrofotometria e cromatografia de Peperomia pellucida L. (H. B. K.)
}

\author{
SILVA,R.M.F. ${ }^{*}$, ; RIBEIRO,J.F.A. ${ }^{2}$; FREITAS,M.C.C. ${ }^{2}$; ARRUDA,M.S.P ${ }^{2}$;; NASCIMENTO,M.N. ${ }^{2}$; \\ BARBOSA,W.L.R. ${ }^{2}$; ROLIM NETO,P.J. ${ }^{1}$ \\ "'Laboratório de Tecnologia dos Medicamentos, Departamento de Ciências Farmacêuticas, Universidade \\ Federal de Pernambuco - Recife- PE - CEP: 50740-521. ${ }^{2}$ Faculdade de Farmácia, Universidade Federal do \\ Pará-Belém - PA - CEP: 66.075-110.rosalimfs@ibest.com.br (Rosali M. F. Silva)
}

\begin{abstract}
RESUMO: O objetivo deste trabalho foi realizar a caracterização físico-química do pó e da tintura, e análise por espectrofotometria e cromatografia do extrato seco de Peperomia pellucida L. (H. B. K.). As metodologias seguiram a Farmacopéia Brasileira IV ed., com exceção da prospecção química, da espectrofotometria, da obtenção do perfil cromatográfico do extrato seco, e determinação do resíduo seco. A prospecção química revelou a presença de saponinas espumídicas; açúcares redutores; proteínas e aminoácidos; fenóis; taninos; flavonóides; esteróides e triterpenóides. Na análise por $C C D$, o melhor perfil da fração flavonoídica foi obtido com $\mathrm{MeOH} / \mathrm{CHOOH}$ (90:10). Foi confirmada, através de CLAE, a presença de 3',4',7-tri-Ometoxiflavona no extrato seco deste material vegetal. Os resultados obtidos contribuem para a determinação de especificações de uma futura monografia em Farmacopéias da Peperomia pellucida L. (H.B.K.).
\end{abstract}

Palavras-chave: Peperomia pellucida, caracterização, cromatografia líquida de alta eficiência, espectrofotometria, cromatografia em camada delgada.

ABSTRACT: Physical chemical characterization and spectrophotometric analysis and chromatography (TLC) of the Peperomia pellucida L. (H. B. K.). The aim of this study was the physical chemical characterization of the powder and the tincture, and the chromatographic and spectrophotometric analysis of the Peperomiapellucida L. (H. B. K.) dry extract. The methodology followed the Farmacopeia Brasileira IV ed., except for the chemical prospection, the chromatographic profile obtained and the spectrophotometry of the dry extract, and determination of dried residues. The chemical prospection revealed the presence of foaming saponins; reducing sugars; proteins and amino acids; phenols; tannins; flavonoids; steroids and triterpenoids; depsideos and depsidones. The best profile from TLC for flavonoidic fraction was obtained with methanol/formic acid (90:10 v/v). HPLC confirmed the presence of 3 ',4',7-tri-methoxyflavone in the dry extract of the plant material. The results obtained in this work should contribute for the determination of specifications for a future monograph on Peperomia pellucida L. (H.B.K.)

Keywords: Peperomia pellucida, characterization, spectrophotometry, thin layer chromatography, high performance liquid chromatography.

\section{INTRODUÇÃO}

A Peperomia pellucida L. (H.B.K.) é planta silvestre, da família Piperaceae. Encontra-se em paises da Ásia, América do Norte, Central (Antilhas) e América do Sul. No Brasil, vai desde a Amazônia até o Paraná. Encontrada em locais úmidos, a Peperomia pellucida L. (H.B.K.) é conhecida popularmente como erva-de-jabuti, coraçãozinho, língua-de-sapo, entre outros (Arrigoni-Blank, 2004).
A erva-de-jabuti é usada na Amazônia para combater a tosse ou a dor de garganta, arritmias cardíacas, sendo ainda antipruriginosa e diurética, utilizada sob a forma de chá ou infusão preparada com as raízes ou com toda a planta (Estrela, 1994; Vieira, 1992). Experimentos realizados por alguns autores divulgam e publicam estudos sobre a abordagem etnofarmacêutica e a fitoquímica da 
Peperomia pellucida L. (H.B.K.) (Araújo, 2006; Barbosa, 2001; Barbosa, 2009, Lameira et al., 2003). Atividades anti-inflamatória, analgésica, antimicrobiana e antihipertensiva também são relatadas para esta erva (Arrigoni-Blank, 2002; Khan, 2002; Khan, 2007; Khan, 2008; Huerta \& Rodriguez, 2003).

Pelo fato de apresentar ciclos curtos de germinação e ser de fácil disseminação, facilitada por fatores naturais como ventos e chuvas, o vegetal germina e cresce com facilidade em áreas úmidas, abundantes em matéria orgânica e ao abrigo da luz solar, o que muitas vezes a faz ser considerada como uma praga em monoculturas (Pereira et al., 2000).

Investigações químicas prévias da Peperomia pellucidaL. (H.B.K.) estabeleceram a ocorrência de apiol, 2,4,5-trimetóxiestireno, flavonas, flavonóis e fitoesteróis (Aquil et al., 1993; Aquil et al., 1994; Manalo et al., 1983). Um estudo químico do extrato metanólico das partes aéreas conduziu ao isolamento de um novo composto $\mathrm{ArC}_{2}$ dimérico, o qual foi denominado pellucidina $A$ juntamente com o conhecido dilapiol, esta última substância pertencente à classe dos fenilpropanóides, e constituinte dos óleos essenciais (Bayma et al., 2000; Manalo et al., 1983).

Alguns pesquisadores isolaram das folhasda Peperomia pellucidaL. (H.B.K.) cinco novos compostos, incluindo duas secolignanas, duas tetrahidrofuranolignanas e uma dihidronaftolenona altamente metoxilada ( $\mathrm{Xu}$ et al., 2006).

Outros estudos relatam a presença de glicosídeos cardíacos, antraquinonas (Aziba et al., 2001), além de flavonóides, saponinas, esteróides e triterpenóides, alcalóides, açúcares redutores, carotenóides, depsídeos e depsidonas, proteínas e aminoácidos, saponina espumídica, fenóis e taninos, e derivados da cumarina (Amador \& Remédios, 2002; Araújo, 2006; Khan \& Omoloso, 2002; Muhammad et al., 1994; Lameira et al., 2003). Flavonóides isolados da folhas da Peperomia pellucida L. (H.B.K.) incluem apigenina, acacetina e isovitexina (Aquil et al., 1993).

O objetivo deste trabalho foi realizar a caracterização físico-química do pó e da tintura, e análise espectrofotométrica e cromatográfica por cromatografia em camada delgada (CCD) e líquida de alta eficiência do extrato seco de Peperomia pellucida L.(H. B. K.).

\section{MATERIAL E MÉTODO}

\section{Matéria Prima Vegetal}

O material botânico foi coletado em julho de 2007, no distrito de Icoaraci, através da Associação Ver-as-ervas ${ }^{\circledR}$, situada na cidade de Belém, Pará - Brasil. Uma exsicata da espécie foi identificada pelo Prof. Dr. Milton Hélio Lima da Silva, do Museu Emilio Goeldi - Pará, e foi registrada com o № MG.191457.

\section{MÉTODO}

Obtenção e caracterização físico-química do pó da Peperomia pellucida L. (H.B.K.)

\section{Processamento da Amostra}

Após a coleta, o material vegetal fresco (planta inteira) foi lavado com água, aspergido com álcool etílico a $70 \%$ e seco em estufa de ar circulante, durante sete dias, à temperatura entre 42 e $45^{\circ} \mathrm{C}$ (Oliveira et al., 1991). Após a retirada do material vegetal da estufa, este foi triturado em moinho de facas, obtendo-se pó seco.

\section{Determinação da distribuição granulométrica do pó}

A repartição granulométrica foi realizada, segundo a Farmacopéia Brasileira IV edição. Os tamises foram utilizados com as seguintes malhas: $10,24,42,60,80$ e 115 mesh, equivalentes a $1,70 \mathrm{~mm}, 710 \mu \mathrm{m}, 355 \mu \mathrm{m}, 250 \mu \mathrm{m}, 180 \mu \mathrm{m}$ e $125 \mu \mathrm{m}$, respectivamente.

\section{Determinações de perda por dessecação e de cinzas totais}

A determinação da perda por dessecação e a quantificação do resíduo não volátil (cinzas totais) do pó de Peperomia pellucida L. (H. B. K.) foram realizadas de acordo com o que preconiza a Farmacopéia Brasileira IV ed. Os testes foram realizados em triplicata.

\section{Obtenção e caracterização Físico-química da Solução Extrativa de Peperomia pellucida L. (H.B. K.)}

\section{Obtenção da tintura de Peperomia pellucida L. (H.B.K.) \\ O método escolhido para a obtenção da} tintura de Peperomia pellucida L. (H. B. K) foi a maceração utilizando a planta inteira. Foi preparada tintura na proporção 1:10 (material vegetal/álcool a $70 \%$ ). Em um reator de aço inoxidável, a droga vegetal ficou em contato com o solvente por 7 dias, com agitação ocasional (Santos, 2000).

\section{Determinação da densidade e do $\mathrm{pH}$}

Foram determinados de acordo com o que preconiza a Farmacopéia Brasileira IV edição. 


\section{Determinação da porcentagem de resíduo seco total \\ Exatamente $1 \mathrm{~mL}$ de cada tintura foi} pipetado e transferido para cápsulas de porcelana previamente taradas. As cápsulas foram colocadas em banho-maria até secura e, em seguida, levadas à estufa a $110^{\circ} \mathrm{C}$, até obter peso constante. Após resfriarem em dessecador, as cápsulas foram pesadas e calculadas as percentagens de resíduo seco (Maciel et al., 2006).

\section{Obtenção do extrato seco}

Para a obtenção do extrato seco da planta, a tintura foi concentrada em evaporador rotativo. Após a evaporação do álcool, foi observada a presença de extrato solúvel em água. Para a retirada total da água, foram adicionadas alíquotas de butanol até a total retirada da água e, em seguida, o extrato foi levado à estufa, em temperatura média de $40^{\circ} \mathrm{C}$, até a total evaporação de resíduos de solvente.

\section{Obtenção da fração flavonoídica}

A fração flavonoídica foi preparada através de extração sólido-líquido. Partindo de $1,015 \mathrm{~g}$ do extrato bruto seco, foram adicionados $10 \mathrm{~mL}$ de hexano P.A e, para facilitar a dissolução, a amostra foi colocada no aparelho de ultrassom durante três minutos e, em seguida, levado à centrifuga por $10 \mathrm{~min}$. Ao retirar a solução da centrífuga, o sobrenadante do resíduo foi separado em béqueres diferentes; o sobrenadante foi deixado à parte e ao resíduo adicionaram-se $10 \mathrm{~mL}$ de hexano; Esta amostra foi levada ao ultrassom e à centrífuga da mesma forma que foi realizado anteriormente. $\mathrm{O}$ processo foi repetido por mais 6 vezes, sempre juntando os sobrenadantes, até que o sobrenadante se tornasse bem claro. Em seguida, a próxima fase foi iniciada a partir do resíduo, mas desta vez com o clorofórmio repetindo-se o mesmo procedimento, diferindo apenas pelo fato de o sobrenadante do clorofórmio ser armazenado separadamente ao do hexano. Nesta segunda fase, foram adicionados 70 $\mathrm{mL}$ de clorofórmio em alíquotas de $10 \mathrm{~mL}$. O resíduo desta segunda fase foi determinado como sendo a fração flavonoídica. Com esta fração flavonoídica, foi determinado o perfil cromatográfico utilizando cromatografia em camada delgada cujo método está descrito a seguir.

\section{Prospecção química do extrato seco}

Na prospecção química foram pesquisados saponinas, açúcares redutores, polissacarídeos, proteínas e aminoácidos, fenóis e taninos, flavonóides, alcalóides, glicosídeos cardíacos, catequinas, derivados benzoquinonas, naftoquinonas, fenantraquinonas, sesquiterpenolactonas e outras lactonas, esteróides, triterpenóides e azulenos.
A prospecção química seguiu a metodologia descrita no Manual para Análise Fitoquímica e Cromatográfica de Extratos Vegetais (Barbosa, 2004).

\section{Saponinas espumídicas}

Foram dissolvidos 50,00 miligramas do extrato seco em $5 \mathrm{~mL}$ de água destilada. Em seguida, diluiu-se para $15 \mathrm{~mL}$ e agitou-se vigorosamente durante $2 \mathrm{~min}$ em tubo fechado. O resultado é considerado positivo para saponina espumídica caso a camada de espuma permaneça estável por mais de meia hora.

\section{Açúcares Redutores}

Foram dissolvidos cerca de 50,00 miligramas do extrato seco em $5 \mathrm{~mL}$ de água destilada. Filtrouse. Adicionou-se $2 \mathrm{~mL}$ do reativo de Fehling A e $2 \mathrm{~mL}$ do reativo de Fehling $B$. Aqueceu-se em banhomaria em ebulição durante $5 \mathrm{~min}$. $\mathrm{O}$ aparecimento de um precipitado vermelho-tijolo indica presença de açúcares redutores.

\section{Polissacarídeos}

Foram dissolvidos 50,00 miligramas do extrato seco em $5 \mathrm{~mL}$ de água destilada. Filtrou-se. Adicionaram-se duas gotas de lugol. $\mathrm{O}$ aparecimento de coloração azul indica resultado positivo.

\section{Proteínas e Aminoácidos}

Foram dissolvidos 30,00 miligramas do extrato alcoólico em $3 \mathrm{~mL}$ de água destilada. Filtrou-se. Adicionou-se $0,5 \mathrm{~mL}$ de solução aquosa de nihidrina a $1 \%$ e aqueceu-se até a ebulição. $O$ aparecimento de coloração violeta persistente indica reação positiva.

\section{Fenóis e Taninos}

Dissolveram-se 50,00 miligramas de extrato seco em $5 \mathrm{~mL}$ de água destilada, filtrou-se e adicionou-se de uma a duas gotas de solução alcoólica de $\mathrm{FeCl}_{3}$ a $1 \%$. Qualquer mudança na coloração ou formação de precipitado é indicativa de reação positiva, quando comparado com o teste em branco (água + Solução de $\mathrm{FeCl}_{3}$ ). Coloração inicial entre o azul e o vermelho é indicativa da presença de fenóis, quando o teste em branco for negativo. Precipitado escuro de tonalidade azul indica presença de taninos pirogálicos (taninos hidrolisáveis) e verde, presença de taninos catéquicos.

\section{Flavonóides}

Dissolveram-se 100,00 miligramas do extrato seco em $10 \mathrm{~mL}$ de metanol. Filtrou-se. Adicionaram-se cinco gotas de $\mathrm{HCl}$ concentrado e raspas de magnésio. O surgimento de uma

Rev. Bras. PI. Med., Campinas, v.15, n.4, supl.I, p.717-726, 2013. 
coloração rósea na solução indica reação positiva. Alcalóides

Dissolveram-se 50,00 miligramas do extrato seco em $5 \mathrm{~mL}$ de solução de $\mathrm{HCl}$ a $5 \%$. Filtrou-se. Separou-se quatro porções de $1 \mathrm{~mL}$ em tubos de ensaio, e adicionaram-se gotas dos reativos abaixo:

a) Reativo de Bouchardat: Aparecimento de precipitado laranja-avermelhado.

b) Reativo de Dragendorff: Aparecimento de precipitado vermelho-tijolo.

c) Reativo de Mayer: Aparecimento de precipitado branco.

\section{Glicosídeos cardíacos}

Dissolveram-se 50,00 miligramas do extrato seco em $5 \mathrm{~mL}$ de metanol. Filtrou-se. Separou-se em duas porções de $2 \mathrm{~mL}$. Na primeira porção, adicionaram-se gotas do reativo de Keede. Coloração azul ou violeta indica reação positiva. $\mathrm{Na}$ segunda porção, adicionaram-se 3 gotas de solução recém-preparada de nitroprussiato de sódio e 3 gotas de solução de hidróxido de sódio $2 \mathrm{~N}$. Coloração roxa intensa indica reação positiva.

\section{Catequinas}

Dissolveram-se 30,00 miligramas do extrato seco em $3 \mathrm{~mL}$ de metanol. Filtrou-se. Adicionou-se $1 \mathrm{~mL}$ de solução aquosa de vanilina a $1 \%$ e $1 \mathrm{~mL}$ de $\mathrm{HCl}$ concentrado. $\mathrm{O}$ surgimento de uma coloração vermelha intensa indica reação positiva.

Derivados Benzoquinonas, Naftoquinonas e Fenantraquinonas

Dissolveram-se 30,00 miligramas do extrato seco em $3 \mathrm{~mL}$ de metanol. Filtrou-se. Adicionaramse 2 gotas de $\mathrm{Na}_{2} \mathrm{CO}_{3}$ a $25 \%, 2$ gotas de formaldeído a $4 \%$ e 2 gotas de o-dinitrobenzeno a $5 \%$. Aqueceuse a mistura em banho-maria. Coloração violeta indica reação positiva.

\section{Sesquiterpenolactonas e outras lactonas}

Dissolveram-se 30,00 miligramas do extrato em $3 \mathrm{~mL}$ de metanol. Filtrou-se. Adicionaram-se 12 gotas de solução alcoólica de cloridrato de hidroxilamina a $10 \%$ e duas gotas de solução metanólica de $\mathrm{KOH}$ a $10 \%$. Aqueceu-se suavemente em banho-maria durante $2 \mathrm{~min}$. Em seguida, esfriou-se e acidificou-se com solução de $\mathrm{HCl}$ a $1 \mathrm{~N}$. Adicionou-se 1 gota de $\mathrm{FeCl}_{3}$ a1\%. O aparecimento de coloração violeta indica reação positiva.

\section{Esteróides e Triterpenóides}

Dissolveram-se 100,00 miligramas do extrato seco em $10 \mathrm{~mL}$ de clorofórmio. Filtrou-se sobre carvão ativado. Transferiu-se o filtrado para um tubo de ensaio completamente seco. Adicionouse $1 \mathrm{~mL}$ de anidrido acético e agitou-se suavemente.
Em seguida, adicionaram-se, cuidadosamente, 3 gotas de $\mathrm{H}_{2} \mathrm{SO}_{4}$ concentrado. Agitou-se suavemente.

Se houver rápido desenvolvimento de cores, que vão do azul evanescente ao verde persistente, indicam resultado positivo.

\section{Azulenos}

Dissolveram-se 20,00 miligramas do extrato seco em $2 \mathrm{~mL}$ de clorofórmio. Filtrou-se concentrando até $0,5 \mathrm{~mL}$ em banho-maria e adicionaram-se 2,5 $\mathrm{mL}$ da solução de $\mathrm{p}$-dimetilaminobenzaldeído. Aqueceu-se em banho-maria durante $5 \mathrm{~min}$. Após esfriar em um funil de decantação, agitou-se com $10 \mathrm{~mL}$ de éter de petróleo. Quando as duas fases estiverem distintas, observa-se a fase aquosa. Quando há presença de proazulenos, a fase aquosa adquire coloração azul, porém quando estes estão em pequena quantidade, a coloração observada é esverdeada.

\section{Espectrofotometria de absorção UV/Visível}

Foram preparadas soluções do extrato bruto $\left(0,033 \mathrm{mg} \mathrm{mL}^{-1}\right)$, da fração flavonoídica $\left(0,014 \mathrm{mg} \mathrm{mL}^{-1}\right)$, e dos padrões de rutina hidratada Sigma-Aldrichi ${ }^{\circledR}$ mín. 95\% lote $128 \mathrm{H} 0176(0,01$ $\mathrm{mg} \mathrm{mL}^{-1}$ ) e de quercetina dihidratada mín. $98 \%$ Sigma-Aldrichi ${ }^{\circledR}$ mín. 95\% lote 035X0720 (0,005 mg $\mathrm{mL}^{-1}$ ), utilizando como solventes água purificada $\mathrm{e}$ metanol. Foi feita varredura entre 200 e 800 nm, utilizando um espectrofotômetro de absorção UVvisível Shimadzu ${ }^{\circledR}$.

\section{Determinação do Perfil Cromatográfico da} Fração Flavonoídica de Peperomia pellucida L. (H. B. K.) por Cromatografia em Camada Delgada

Para a Cromatografia em Camada Delgada (CCD), primeiramente foram utilizadas placas de sílica de fase normal, confeccionadas no próprio laboratório, e ativadas a $105^{\circ} \mathrm{C}$ por cerca de $15 \mathrm{~min}$, para a análise da amostra em diversos eluentes, verificando-se em qual deles a amostra apresentaria melhor separação em bandas. Para a análise em cromatografia em fase reversa, foram utilizadas placas padrões, pré-fabricadas, RP-18 Merck $^{\circledR}$ (Lopes, 2007). Para a visualização das substâncias, foi utilizada a radiação ultravioleta em 254 ou 365 $\mathrm{nm}$ e como revelador o cloreto férrico a $5 \%(\mathrm{p} / \mathrm{v})$ ou difenilborato de aminoetanol (NP-PEG) (Carvalho et al., 2006; Dourado \& Ladeira, 2008; Wagner \& Bladt, 2001; Verlag, 1981). A solução da amostra aplicada nas placas foi preparada com concentração de 4,2 $\mathrm{mg} \mathrm{mL}^{-1}$ (fração flavonoídica/metanol).

Determinação do Perfil Cromatográfico da Fração Flavonoídica de Peperomia pellucida L. (H. B. K.) por Cromatografia a Líquido de Alta Eficiência

Rev. Bras. PI. Med., Campinas, v.15, n.4, supl.I, p.717-726, 2013. 


\section{Preparação das Amostras}

Foram preparadas soluções de amostras da fração flavonoídica e do extrato seco da $P$. pellucida L. (H.B.K.) com concentrações de $8,40 \mathrm{mg} / \mathrm{mL}$, cada uma, utilizando como solventes água purificada e metanol.

\section{Preparação dos Padrões}

Foram preparadas soluções de padrões de quercetina dihidratada, rutina hidratada, epicatequina e catequina, utilizando a mesma concentração e os mesmos solventes das amostras. Todos os padrões foram obtidos do fabricante Sigma-Aldrichi ${ }^{\circledR}$.

Equipamento e Parâmetros Cromatográficos

Foi utilizado um cromatógrafo líquido de alta eficiência Shimadzu ${ }^{\circledR}$, composto por duas bombas, modelo LC-10AD, detector com único sinal de absorvância na região do ultravioleta, operando com comprimento de onda em 270 e $320 \mathrm{~nm}$ modelo SPD-10AV, degaseificador de membrana, modelo DGU-14A, injetor de amostras Rheodyne 7752i, com alça de amostragem de 20 $\mu \mathrm{L}$, interface de comunicação Shimadzu ${ }^{\circledR}$, modelo CBM-10A acoplado a microcomputador Pentium II com software de integração Class LC-10A.

Os parâmetros cromatográficos utilizados foram fluxo de $1,0 \mathrm{~mL} / \mathrm{min}$, uma coluna Gemini ${ }^{\circledR}$ C18, $250 \times 4,6 \mathrm{~mm}, 5 \mu \mathrm{m}$, um volume de injeção de $20 \mu \mathrm{L}$ e fase móvel gradiente de ácido fórmico a $1 \%$ em acetonitrila. Foi preparada uma solução de ácido fórmico a 1\% em água, e aumentou-se a proporção de ácido fórmico a $1 \%$ em acetonitrila, de 5 a $100 \%$, durante 60 minutos.

Determinação do Teor do Marcador 3',4',7-triO-metoxiflavona Extrato Seco de Peperomia pellucida L. (H. B. K.) por Cromatografia a Líquido de Alta Eficiência

O teor do marcador 3',4',7-tri-Ometoxiflavonano extrato seco de Peperomia pellucida L. (H.B.K.) foi analisado, em triplicata, por cromatografia a líquido de alta eficiência. Foram pesados $20 \mathrm{mg}$ de cada amostra, e preparada uma curva de calibração, nas concentrações de 2, 10, 20, 40 e 100 ppm, utilizando como solvente a acetonitrila e como marcador 3',4',7-tri-O-metoxiflavona, que foi isolado e identificado por técnicas de Ressonância Magnética Nuclear (Silva, 2010).

Foi utilizado um cromatógrafo a líquido de alta eficiência Shimadzu ${ }^{\circledR}$, composto por duas bombas, modelo LC-10AD, detector com único sinal de absorvância na região do ultravioleta, operando com comprimento de onda em 270 e $400 \mathrm{~nm}$ modelo SPD-10AV, degaseificador de membrana, modelo DGU-14A, injetor de amostras Rheodyne $7752 i$, com alça de amostragem de 20 $\mu \mathrm{L}$, interface de comunicação Shimadzu ${ }^{\circledR}$, modelo CBM-10A acoplado a microcomputador Pentium II com software de integração Class LC-10A

Os parâmetros cromatográficos utilizados foram coluna Gemini Phenomenex ${ }^{\circledR}$ C18 (250 x $4,6 \mathrm{~mm}, 5 \mu \mathrm{m}, 110 \AA$ ), pré-coluna Phenomenex ${ }^{\circledR} \mathrm{C} 18$ $(4,0 \times 3,0 \mathrm{~mm}, 5 \mu \mathrm{m})$, fase móvel acetonitrila:água (54:46), fluxo de $1 \mathrm{~mL} / \mathrm{min}$., volume de injeção 20 $\mu \mathrm{L}$ e comprimento de onda $342 \mathrm{~nm}$.

\section{RESULTADO E DISCUSSÃO}

Obtenção e Caracterização físico-química do pó de Peperomia pellucida L. (H. B. K.)

\section{Processamento da Amostra}

Como foram coletados $7 \mathrm{~kg}$ de Peperomia pellucida L. (H.B.K.) fresca, após a secagem na estufa e a moagem, obtiveram-se $280 \mathrm{~g}$ do pó da planta seca. O que significa um rendimento de $4 \%$ de planta seca em relação à planta fresca.

\section{Determinação da Granulometria do Pó}

Na granulometria do pó de Peperomia pellucida L. (H.B.K.), ao comparar os resultados com a classificação da Farmacopéia Brasileira IV ed., concluiu-se que o pó desta planta como sendo um pó grosso (Figura 1).

A distribuição granulométrica de drogas vegetais determina a superfície de contato disponível para interação com o solvente utilizado na obtenção do derivado vegetal. É um parâmetro preliminar importante para a escolha do processo extrativo e do solvente adequado, já que influencia diretamente na eficiência do processo extrativo (Santos, 2000; Migliato et al., 2007).

\section{Determinação de Perda por Dessecação}

A média do valor obtido da perda por dessecação da Peperomia pellucida L. (H. B. K) foi de $9,5 \%$, apresentando-se de acordo com a Farmacopéia Brasileira IV ed., na qual este resultado pode variar de 8 a $14 \%$. Esta determinação é importante para o controle microbiológico, pois, excesso de água na droga vegetal favorece o crescimento de fungos e bactérias, podendo também levar à hidrólise dos constituintes (Sharapin, 2000).

\section{Determinação de Cinzas Totais}

Teor de cinzas totais é o valor que determina o teor de sílica, principalmente areia e terra silícea presente na droga (Sharapin, 2000).

Após a calcinação das amostras, a média do valor obtido foi de $38,57 \%$.

O valor aceitável no teor de cinzas totais da Peperomia pellucida L. (H. B. K.) ainda não foi

Rev. Bras. PI. Med., Campinas, v.15, n.4, supl.I, p.717-726, 2013. 


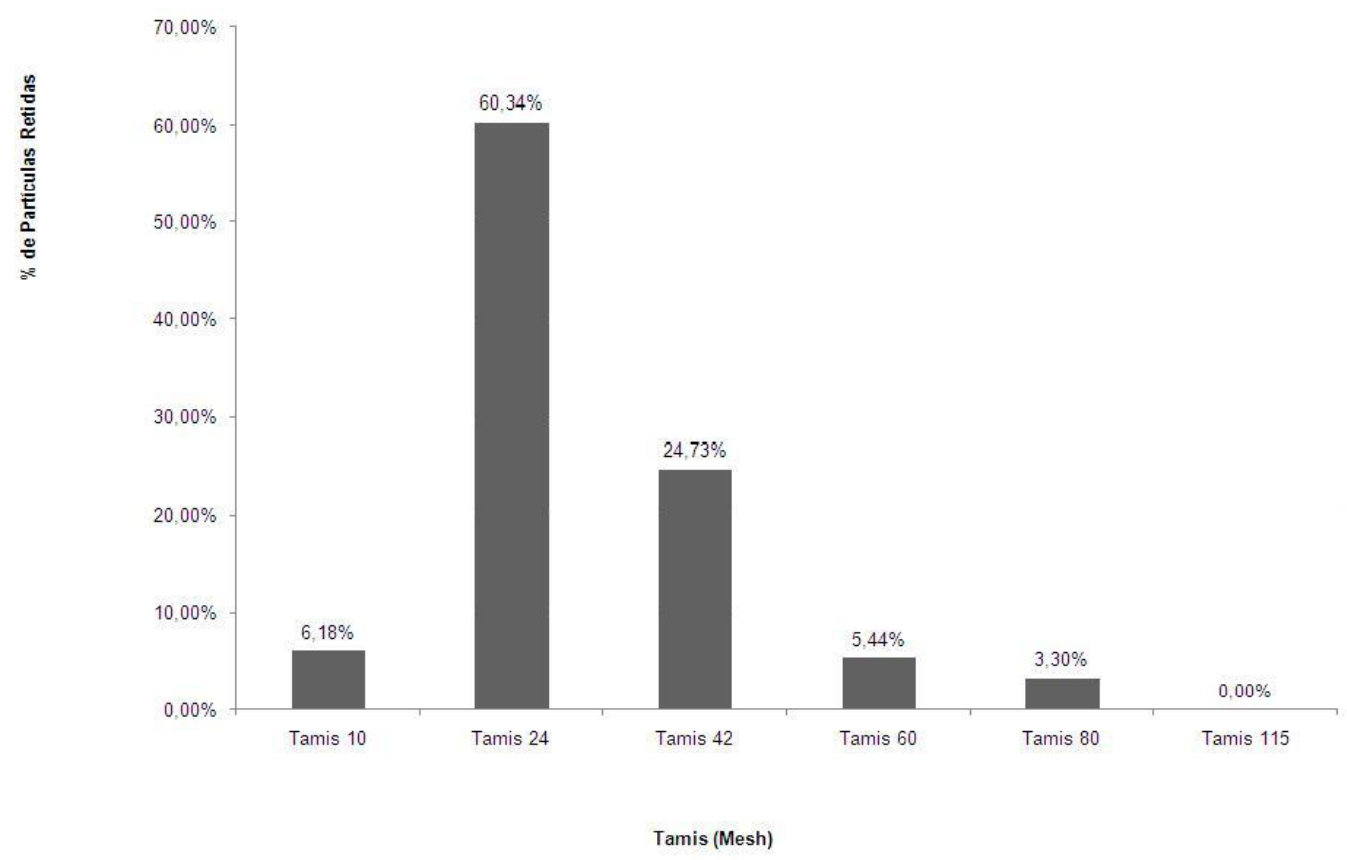

FIGURA 1. Determinação granulométrica do pó de Peperomia pellucida L. (H.B.K.).

estabelecido em nenhuma monografia.

Obtenção e caracterização físico-quimica da solução extrativa de Peperomia pellucida L. (H.B.K.)

\section{Obtenção da Tintura}

Foram obtidos $1800 \mathrm{~mL}$ de tintura da Peperomia pellucida L. (H. B. K).

\section{Determinação da densidade}

$O$ valor obtido para a densidade da tintura da Peperomia pellucida L. (H. B. K) foi 0,8660 $\mathrm{g} \mathrm{mL}^{-1}$.

\section{Determinação do pH}

O valor obtido para o $\mathrm{pH}$ foi 6,57 .

\section{Determinação da porcentagem de resíduo seco total}

Foram obtidos $1,39 \%$ de resíduo seco total. Os valores aceitáveis para a densidade, $\mathrm{pH}$ e porcentagem de resíduo total seco para a tintura da Peperomia pellucida L. (H. B. K) ainda não foram estabelecidos em nenhuma monografia.

\section{Obtenção do Extrato Seco}

O extrato seco obtido a partir da concentração da tintura da Peperomia pellucida L. (H. B. K)foi de $28,87 \mathrm{~g}$. O que representa um rendimento de $11,5 \%$ em relação à planta seca e de $0,41 \%$ em relação à planta fresca.

$\mathrm{Na}$ obtenção do extrato seco, verificouse que a planta apresenta baixo rendimento. $\mathrm{E}$ se os estudos farmacológicos e tecnológicos viabilizarem a Peperomia pellucida L. (H. B. K) para a produção de medicamentos fitoterápicos, necessitar-se-ia de produção da mesma em grande escala.

\section{Obtenção da fração flavonoídica}

A quantidade total obtida de fração flavonoídica a partir de $1,015 \mathrm{~g}$ de extrato seco foi $0,8584 \mathrm{~g}$, ou seja, $84,62 \%$ do extrato seco.

\section{Prospecção Química do extrato seco}

$\mathrm{Na}$ análise fitoquímica da droga, foi identificada a presença de saponina espumidica; açúcares redutores; proteínas e aminoácidos; fenóis e taninos; flavonóides; esteróides e triterpenóides.

\section{Espectrofotometria de Absorção UV/Visível}

Conforme o espectro apresentado após a varredura das amostras (Figura 2), a banda I apresentou absorção máxima em $332 \mathrm{~nm}$, e a banda II apresentou absorção máxima nas faixas de comprimento de onda entre 270 e $272 \mathrm{~nm}$. A Banda Il pode ser considerada como sendo de origem do sistema do anel A Benzoil, e a banda I pode ser originada do sistema do anel B cinamoil (Markham \& Mabry, 1975). 
A espectrofotometria mostrou que a fração flavonoídica e o extrato seco apresentaram comportamentos semelhantes no espectro, divergindo do comportamento dos padrões utilizados, rutina e quercetina; logo, é provável que esta fração se trate de uma mistura de flavonóides e, se a rutina e a quercetina estiverem presentes, estas devem estar em pequenas quantidades.

Determinação do Perfil Cromatográfico da Fração Flavonoídica de Peperomia pellucida L. (H. B. K.) por Cromatografia em Camada Delgada

$\mathrm{Na}$ análise por CCD, o eluente que apresentou melhor separação da mistura foi o $\mathrm{MeOH} /$ $\mathrm{CHOOH} 90: 10$, sobre cromatoplacas de gel de sílica de fase reversa, usando cloreto férrico a $5 \%$ como revelador, apresentando duas manchas com $\operatorname{Rf} 0,63$ e 0,75 (figura 3 ). Porém as bandas apresentadas pela fração flavonoídica de Peperomia pellucida L. (H.B.K.) não ficaram bem definidas, dificultando sua comparação com padrões de flavonóides. Porém, Silva, em 2010, conseguiu isolar, através de cromatografia a líquido de alta eficiência, o 3',4',7-tri-O-metoxiflavona, confirmando a presença de flavonóides em Peperomia pellucida L. (H.B.K.). A presença desse possível flavonoide como marcador na solução extrativa está demonstrada abaixo.

\section{Determinação do Perfil Cromatográfico da Fração Flavonoídica de Peperomia pellucida L. (H. B. K.) por Cromatografia A Líquido de Alta Eficiência \\ Os resultados estão apresentados nas} Figuras 4 e 5.

Comparando-se os tempos de retenção do extrato seco e da fração flavonoídica, verificase a presença de flavonóides em torno de 20 minutos já que ambos os cromatogramas foram feitos no mesmo sistema cromatográfico. Quando observados por espectrofotometria no ultravioleta, os cromatogramas, exibidos na faixa de tempo de retenção próximos aos 20 minutos apresentaram o espectro com dois máximos de absorção, um que ocorreu na faixa de $220-285 \mathrm{~nm}$ (banda II) e o outro que ocorreu na faixa de $300-400 \mathrm{~nm}$ (banda I).

O intervalo entre 29 e 30 min apresenta um pico referente ao padrão quercetina; entre 31 e 32 min a catequina; entre 19 e $20 \mathrm{~min}$, a rutina; e entre 11 e 12 min, a epicatequina. Pelo tempo de retenção e comparando-se com os obtidos no extrato seco e na fração flavonoídica pode-se inferir que exista flavonóide, já que tanto as amostras quanto os padrões foram feitos nas mesmas condições cromatográficas. Ao comparar com estudos de outros materiais vegetais que encontram-se em andamento pelo grupo de pesquisa, sugere-se a presença de isoflavonas, mas estas precisariam ser isoladas e identificadas através de RMN e espectro de massa, para serem utilizados como possíveis marcadores.

Determinação do Teor do Marcador 3',4',7-tri-O-metoxiflavona em Peperomia pellucida L. (H. B. K.) por Cromatografia a Líquido de Alta Eficiência

A média dos valores obtidos para o teor de 3',4',7-tri-O-metoxiflavona em cada $100 \mathrm{~g}$ da amostra foi $17,66 \mathrm{mg}$.

A 3',4',7-tri-O-metoxiflavona apresentou tempo de retenção em 15,26 min.

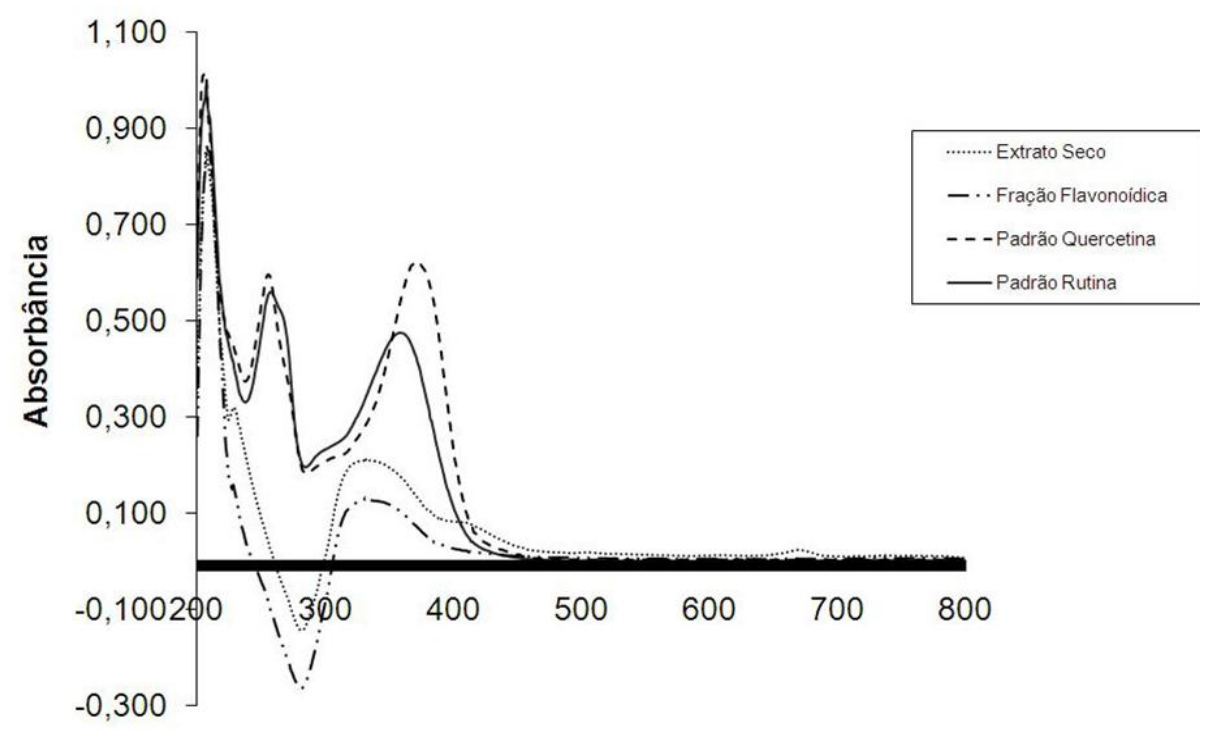

Comprimento de onda $(\mathrm{nm})$

FIGURA 2. Espectro de varredura de 200 a 800 nm, do extrato seco, fração flavonoídica, e padrões de rutina e de quercetina. 


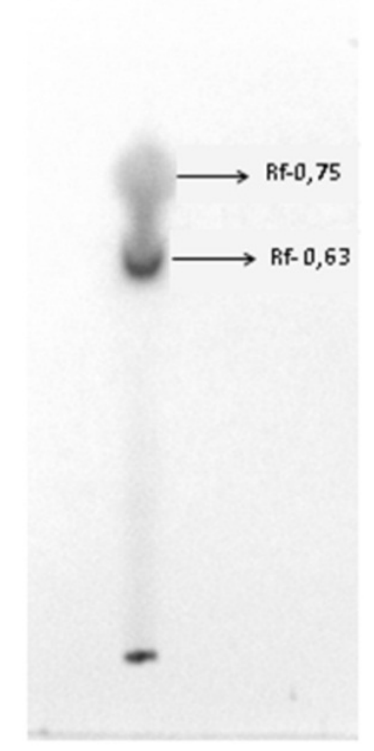

FIGURA 3. Placa de Cromatografia em Camada Delgada da solução com concentração de $4,2 \mathrm{mg}$ $\mathrm{mL}^{-1}$ (fração flavonoídica/metanol) de Peperomia pellucida L. (H.B.K.), utilizando como eluente $\mathrm{MeOH} /$ $\mathrm{CHOOH}$ 90:10.

\section{CONCLUSÃO}

No presente trabalho, foi possível concluir que o material vegetal apresenta baixo rendimento. Na espectrofotometria, determinou-se que os flavonóides presentes no material vegetal provavelmente não se tratam de quercetina ou rutina. Contudo, de acordo com a cromatografia líquida de alta eficiência, sugere-se que a fração flavonoídica da Peperomia pellucida L. (H.B.K.) trata-se de uma mistura de flavonóides os quais precisam ser isolados e identificados através de métodos espectrométricos, para caracterizar novos marcadores. Todavia, já foi confirmada a presença de 3',4',7-tri-O-metoxiflavona no extrato seco deste material vegetal.

Os resultados obtidos com a perda por dessecação, determinação de cinzas totais, determinação de $\mathrm{pH}$, densidade e porcentagem de resíduo seco total contribuem para especificações de futura monografia farmacopeica da Peperomia pellucida L. (H.B.K.), insumos vegetais de maior uniformidade, garantindo maior qualidade e padronização para o desenvolvimento e produção

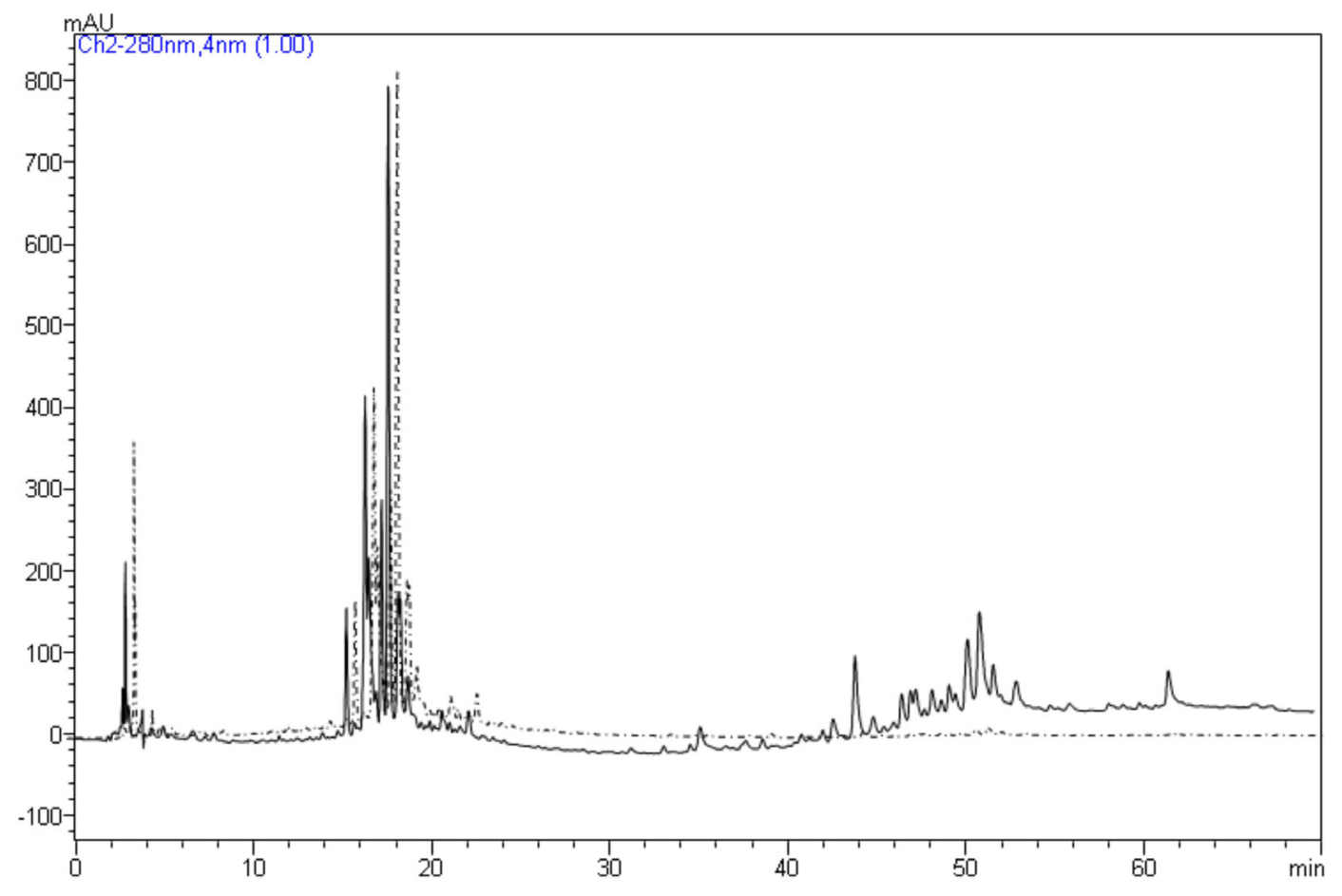

FIGURA 4. (_)Extrato seco da Peperomia pellucida L. (H.B.K.); (-.-.) Fração flavonoídica da Peperomia pellucida L. (H.B.K.)utilizando um gradiente exploratório de 5 a 100\% de MeCN em 60 min, varredura de 200 a 400 nm, injeção de $20 \mu \mathrm{L}$. 


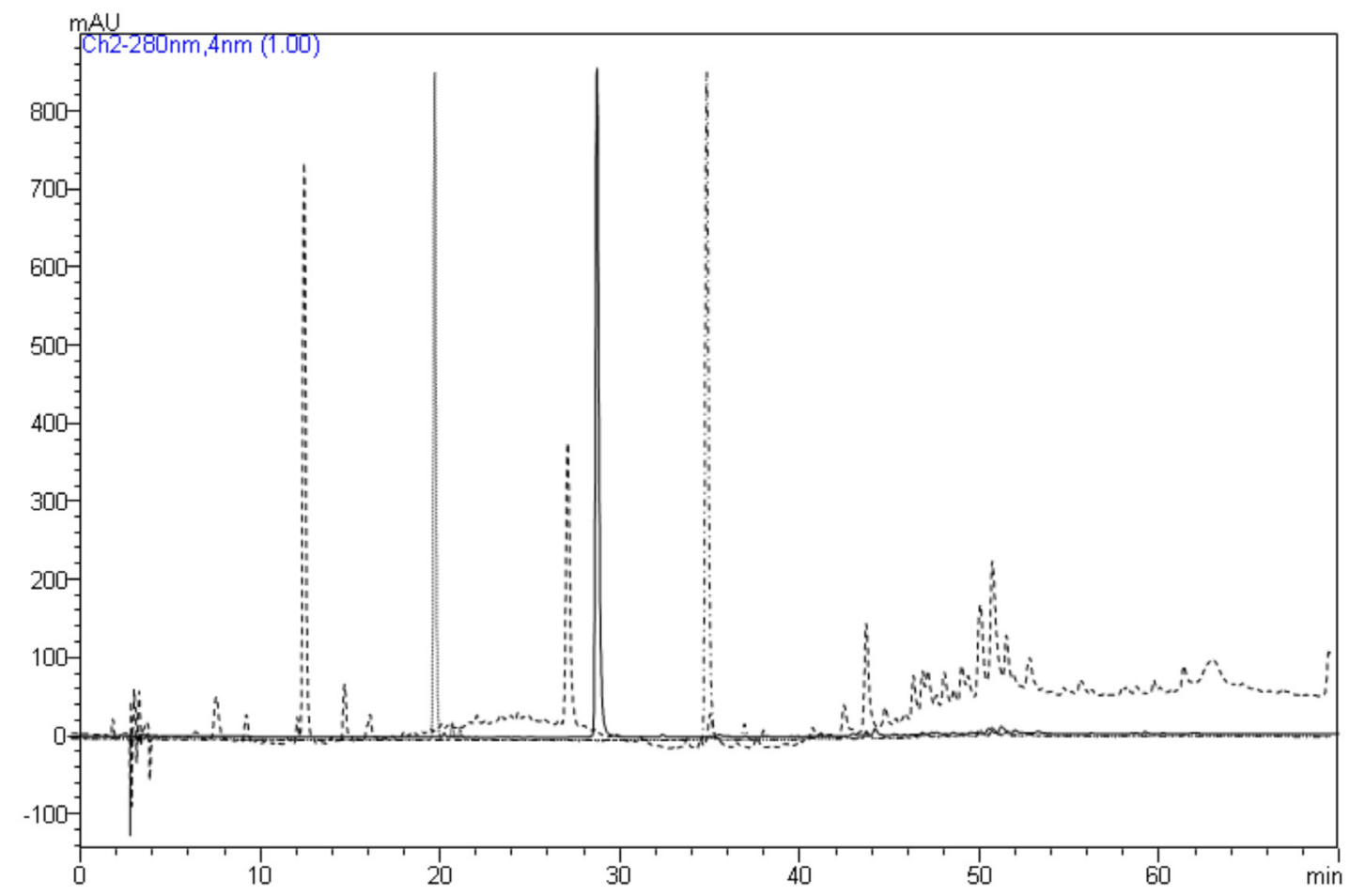

FIGURA5. (_)Padrão de quercetina; (....)Padrão de rutina; (---)Padrão de epicatequina; (-.-) Padrão de catequinagradiente exploratório de 5 a 100\% de MeCN em 60 min, varredura de 200 a 400 nm, injeção de $20 \mu \mathrm{L}$.

de fitoterápicos seguros e eficazes.

\section{AGRADECIMENTOS}

À Coordenação de Aperfeiçoamento de Pessoal de Nível Superior (Capes), pela bolsa concedida.

\section{REFERÊNCIA}

AMADOR, E.C.C.; REMÉDIOS, A.G.M.. Abordagem Fitoquímica da Erva-de-Jabuti (Peperomia pellucida).2002, 28p. Trabalho de Conclusão de Curso do Departamento de Farmácia da Universidade Federal do Pará, Belém.

AQUIL, M.; KHAN, I.Z.; AHMAD, M. B. Flavonoids from Peperomia pellucida.Scientist of Physical Science.5; p. 213-215, 1993.

AQUIL, M.; RAHMAN, F.A.; AHMAD, M.B.A new flavonol glycoside from Peperomia pellucida. Scientist ofPhysical Science.6, p.141-143, 1994. ARAÚJO, S.C. Utilização de LC-DAD na Detecção e Caracterização de Flavonóides do Extrato Etanólico de Peperomia pellucida (L.) H.B.K. 2006. 39p.Trabalho de Conclusão de Curso, Faculdade de Farmácia, Universidade Federal do Pará, Belém.

ARRIGONI-BLANK, M. F.Seed germination, phenology, and antiedematogenic activity of Peperomia pellucida (L.) H. B. K. 2002. BMC Farmacologia. Disponível em: www.biomedcentral.com/1471-2210/2/12 . Acesso em:
12 abril 2008.

ARRIGONI-BLANK, M.F. Anti-inflammatory and analgesic activity of Peperomia pellucida (L). HBK (Piperaceae). Journal of Ethnopharmacology,91, p. 215-218, 2004. AZIBA, P.I.; ADEDEJI, A.; EKOR, M.; ADEYEMI, O.; Analgesic activity of Peperomia pellucida aerial parts in mice. Fitoterapia. 72, p. 57-58, 2001.

BARBOSA, W.L.R. 2004. Manual para Análise Fitoquímica e Cromatográfica de Extratos Vegetais, Belém - Pa: Revista Cientifica da UFPA, vol. 4, 2001. Disponível em http://www.ufpa.br/rcientifica. Acesso em: 12 de abril de 2007.

BARBOSA, W.L.R. Levantamento etnofarmacêutico da fitoterapia tradicional em Igarapé-Miri-Pará.CD-Rom. In: VII REUNIÃO ESPECIAL DA SOCIEDADE BRASILEIRA PARA O PROGRESSO DA CIÊNCIA. VII RE - SBPC. V.1. , 2001, Manaus. CD-Rom.

BARBOSA, W.L.R. Aspectos da Etnofarmácia baseados na Assistência Farmacêutica aplicados à Fitoterapia Popular. In Barbosa, WLR (org.) Etnofarmácia: Fitoterapia Popular e Ciência Farmacêutica. Belém: NUMA-UFPA, 2009. 169p.

BAYMA, J.C.; ARRUDA, M.S.P.; MULLER, A.H.; ARRUDA, A.C.; CANTO, W.C.; A dimeric $\mathrm{ArC}_{2}$ compound from Peperomia pellucida. Phytochemistry, 55, p. 779 782, 2000.

DOURADO, R.S. \&LADEIRA, A.M. Identificação de flavonóides em Hypericum cordatum (Vell.) N. Robson (Clusiaceae). Revista Brasileira de Botânica, v.31, n.4, p. 611-620, 2008.

CARVALHO, C.M.G.; PRUDENTE, L.R.; PEREIRA, A.C.;

Rev. Bras. PI. Med., Campinas, v.15, n.4, supl.I, p.717-726, 2013. 
DE PAULA, J.R.; BARA, M.T.F. Avaliação da Qualidade de Extratos Vegetais. Revista Eletrônica de Farmácia. v. 3 (2), p. 53-62, 2006.

ESTRELA, e. Plantas Medicinales Amazonicas: Realidad y Perspectivas. Quito: Programa de Las Nacionales Unidas para el Desarrollo (PNVD), 1994. p.265.

FARMACOPÉIA BRASILEIRA. IV ed. Parte I. São Paulo: Atheneu, 1988. p.V2.14. - V2.14.4; V2.17.-V2.17.3.

HUERTA, E.I.; RODÍGUEZ, J.E.T. Toxicología Aguda Oral de la decocción la Peperomia pellucida (L.) H.B.K. (Corazón de hombre). Toxicologia Clínica, Sertox. 2003. Disponível em: http://www.sertox.com.ar/retel/ default.htm. Acesso em 20 ago 2007.

KHAN, M.R. Antibacterial activity of Hygrophila stricta and Peperomia pellucida. Fitoterapia, 73, 251-254, 2002.

KHAN, M.R.; OMOLOSO, A.D. Antibacterial activity of Hygrophila stricta and Peperomia pellucida. Fitoterapia. 73, p. 251-254, 2002.

KHAN, M.R. Antipyretic Activity of Peperomia pellucida Leaves in Rabbit, Turk Journal of Biology, 32, 37-41, 2007.

KHAN, A. Neuropharmacological effects of Peperomia pellucida L. (H.B.K.) leaves in mice. DARU. 16, 35-40, 2008.

LAMEIRA, O.A.; PAIVA, J.S.; OLIVEIRA, E.C.P; PINTO, J.E.P. Fenologia e Análise Fitoquímica de Plantas Medicinais de Ocorrência na Amazônia. 2003. p. 1-6. Disponível em: http://www.abhorticultura.com.br/ biblioteca/arquivos/Download/Biblioteca/44_701.pdf. Acesso em : 21 set. 2010.

LOPES, J.L.C. Cromatografia em Camada Delgada. In: Collins, C.H; Braga, G.L; Bonato, P.S. Fundamentos de Cromatografia; São Paulo: Ed. UNICAMP, 2007. p. 67-85.

MACIEL, R.L., MOREIRA-CAMPOS, L.M., SILVA, B.C., BRANDÃO, M.G.L. Características físico-químicas e químicas e estudo preliminar de estabilidade de tinturas preparadas com espécies de arnica Lychnophora em comparação com Arnica Montana. Revista Brasileira de Farmacognosia. Jan/Mar, 16(1), 99-104, 2006.

MARKHAM, K.R.; MABRY, T.J. The Flavonoids. Academic press: New York, 1975, p. 46 - 90.

MANALO, J.B.; HAN, B.H.; HAN, Y.N.; PARK, M.H.; ANZALDO, F.E. Studies on ether-soluble neutral compounds of Peperomia pellucida.Natural Products Research. Inst., Seoul Natl. Univ. Univ., Seoul, S. Korea.
Archives of Pharmacal Research. ISSN: 0253-6269, 6(2), p. 133-6, 1983.

MIGLIATO, K.F.; MOREIRA, R.R.D.; MELLO, J.C.P.; Sacramento, L.V.S.; Corrêa, M. A.; Salgado, H.R.N. Controle da qualidade do fruto de Syzygium cumini (L.) Skeels. Revista Brasileira de Farmacognosia, v. 17(1), p. 94-101, 2007.

MUHAMMAD, A.; RAHMAN, F.A.; AHMAD, M.B. A new flavonol glycoside from Peperomia pellucida. Scientist of Physical Sciences. Department Chemistry, University Maiduguri, Borno, Nigeria. ISSN: 0970-9150, 1994, 6(1), p. 141-3, 1994.

OLIVEIRA, F.;AKISUE, G.;AKISUE, M. K. Farmacognosia. São Paulo: Editora Atheneu, 1991. p.16-18.

PEREIRA, R.C.A.; MARINHO, J. T. S.; SALES, F.; AZEVEDO, K. S. Manejo e controle de plantas invasoras na cultura do café no Acre. Instruções Técnicas. Acre: Empresa Brasileira de Pesquisa Agropecuária - Embrapa, ISSN 0104-9038, n 30, set/2000, p. 1 - 3.

SANTOS, E.V.M. Extração de matérias-primas vegetais. In: Sharapin, N. Fundamentos de tecnologia de Produtos Fitoterápicos. Santafé de Bogotá: Cyted. 2000. p. 27-60.

SHARAPIN, N. Fundamentos de tecnologia de Produtos Fitoterápicos. Santafé de Bogotá: Cyted, 2000. p 145-157.

SILVA, R.M.F. Peperomia pellucida L. (H.B.K.): Obtenção Tecnológica de Formas Farmacêuticas. 2010. 186p. Tese (Doutorado - Área de concentração em Produção e Controle de Medicamentos). Departamento de Ciências Farmacêuticas, Universidade Federal de Pernambuco, Recife.

WAGNER, H. \&BLADT, S.Plant Drug Analysis. A Thin Layer Chromatography Atlas. Photographs by V. Rickl. Springer, Second Edition, 2001. p. 196.

VERLAG, G.F. Pharmazeutische Biologie. 4-Drogenanalyse II: Inhaltsstoffe und Isolierungen. New York: Stuttgart, 1981, p. 117 a 128.

VIEIRA, L.S. Fitoterapia da Amazônia. Manual das Plantas Medicinais (A Farmácia de Deus). $2^{\mathrm{a}}$ ed. São Paulo: Editora Agronômica Ceres Ltda, 1992. p. 126-127.

XU, S.; LI, N.; NING, M. ZHOU, C. YANG, Q.; WANG, M. Bioactive Compounds from Peperomia pellucida. Journal of Natural Products. vol. 69, p. $247-250$, 2006. 